\title{
The Role and Experience of Sudan in Assisting To Develop and Implement National Drug Policies
}

\author{
Abdeen Mustafa Omer
}

Occupational Health Administration, Ministry of Health,

*Corresponding author

Abdeen Mustafa Omer, Occupational Health Administration, Ministry of Khartoum, Sudan

Health, Khartoum, Sudan. E-mail: abdeenomer2@yahoo.co.uk

Submitted: 24 Aug 2019; Accepted: 07 Sep 2019; Published: 19 Nov 2019

\begin{abstract}
The strategy of price liberalisation and privatisation had been implemented in Sudan over the last decade, and has had a positive result on government deficit. The investment law approved recently has good statements and rules on the above strategy in particular to pharmacy regulations. Under the pressure of the new privatisation policy, the government introduced radical changes in the pharmacy regulations. The 2001 Pharmacy and Poisons Act and its provisions established the Federal Pharmacy and Poison Board (FPPB). All the authorities of the implementation of Pharmacy and Poisons Act were given to this board. This article provides an overview of the impact of the pharmaceutical regulations on the quality of medicines on the Sudanese market from the perspective of the pharmacists working with drug importing companies. The information necessary to conduct the evaluation was collected from 30 pharmacists who are the owners or shareholders in medicines'importing companies. The participants were selected randomly. $89 \%$ of respondents considered the medicines on the Sudanese market are generally of good quality. The design of the research itself may be considered inadequate with regard to selection process. However, the authors believe it provides enough evidence, and the current pharmaceutical regulations have some loopholes. The Pharmacy, Poisons, Cosmetics and Medical Devices Act-2001 and its regulation should be enforced. The overall set-up including the Act itself needs to be revised. The emerging crisis in pharmacy human resources requires significant additional effort to gather knowledge and dependable data that can inform reasonable, effective, and coordinated responses from government, industry, and professional associations. Furthermore research should be carried out to understand the scope, magnitude directions of the migratory flows, within and outside the country, as well as the characteristics and skills of the emigrated pharmacists.
\end{abstract}

Keywords: Counterfeits Medicines, Drug Importers, and Quality of Medicines, Regulatory Authorities
Abbreviations
CMSPO:Central Medical Supplies Public Organization
CRC: Centre of Regulation and Competition
DAP: Drug Action Programme
DOP: Department of Pharmacy
FGDOP:Federal General Directorate of Pharmacy
FMOH: Federal Ministry of Health
FPPB: Federal Pharmacy and Poison Board
GMP: Good Manufacturing Practice
KS: $\quad$ Khartoum State
MOAR: Ministry of Animal Resources
MOH: Ministry of Health
NGOs: Non Governmental Organizations
NDP: National Drug Policy
RDFs: Revolving Drug Funds
SPSS: Statistical Package for Social Sciences
UK: United Kingdom
USA: United States of America
WHO: World Health Organization

\section{Introduction}

The World Health Organisation has defined drug regulation as a process, which encompasses various activities, aimed at promoting and protecting public health by ensuring the safety, efficiency and quality of drugs, and appropriateness accuracy of information [1]. Medicines regulation is a key instrument employed by many governments to modify the behaviour of drug systems. The regulation of pharmaceuticals relates to control of manufacturing standards, the quality, the efficacy and safety of drugs, labelling and information requirements, distribution procedures and consumer prices [2]. To assure quality of medicines, in most countries registration is required prior to the introduction of a drug preparation into the market. The manufacturing, registration and sale of drugs have been the subject of restricts regulations and administrative procedures worldwide for decades [3]. Nobody would seriously argue drugs should be proven to be $100 \%$ safe. No set of regulations could achieve that goal, because it is impossibility and all drugs carry some risk [4].

Stringent drug regulation was introduced across many countries in the 1960s following the thalidomide disaster, and had since been embraced by the industry as a commercial essential seal of safety and quality [5]. In spite of the measures, many countries, especially 
developing ones face a broader range of problems. In several developing countries drug quality is a source of concern. There is a general feeling there is a high incidence of drug preparations, which are not of acceptable quality [6]. For example, about $70 \%$ of counterfeit medicines were reported by developing countries [7]. Reports from Asia, Africa, and South America indicate 10\% to 50 $\%$ of consider using prescribed drugs in certain countries may be counterfeit [8]. For instance, in Nigeria fake medicines may be more than $60-70 \%$ of the drugs in circulation, and 109 children died in 1990 after being administered fake Paracetamol [9,10]. In Gambia the drug registration and control system resulted in the elimination of 'drug peddlers' and certain 'obsolete and harmful' drugs, as well as a large decrease in the percentage of brand and combination drugs [11]. The percentage of drugs failed quality control testing was found to be zero in Colombia, but $92 \%$ in the private sector of Chad [12]. Hence, it is very difficulty to obtain an accurate data. The proportion of drugs in the USA marketplace are counterfeit is believed to be small - less than 1 percent [12]. In reported two cases of counterfeit medicines found their way into legitimate medicine supply chain in the UK in 2004 [13].

Poor quality drug preparations may lead to adverse clinical results both in terms of low efficacy and in the development of drug resistance [14]. Regulations are the basic devices employed by most governments to protect the public health against substandard, counterfeit, low quality medicines, and to control prices. Thus, thorough knowledge of whether these regulations produce the intended effects or generate unexpected adverse consequences is therefore critical. The World Health Organisation (WHO) undertook a number of initiatives to improve medicines quality in its member states and promote global mechanisms for regulating the quality of pharmaceutical products in the international markets. But, there are not any WHO guidelines on how to evaluate the impact of these regulations. There are numerous reports concerning drug regulations, but the published work on the impact of these regulations on the quality of medicines moving in the international commerce has been scarce [15]. Findings from most published studies lack comparable quantitative information that would allow for objective judging whether and by how much progress on the various outcomes have been made by the implementation of the pharmaceutical regulations. To ignore evaluations and to implement drug regulation based on logic and theory is to expose society to untried measures in the same way patients were exposed to untested medicines [15].

\section{Aims and objectives}

The main purpose of this article is to analyse and determine the opinion of a group of pharmacists who are the owners or shareholders in the Sudanese medicine importing companies and their perception concerning the effects of the government's new Pharmacy, Poisons, Cosmetics and Medical Devices Act has had on the quality of medicines in Sudan. To achieve this purpose the following questions would be answered:

1. Do the Sudan pharmacy legislations prohibit marketing of low quality medicines?

2. What is the impact of the transfer of veterinary medicines registration system to the Ministry of Animal Resources after the approval of the Pharmacy and Poisons Act 2001?

3. Does pre-marketing analysis of medicines help to detect the counterfeit medicines?

4. Does importation of non-registered - medicines by the government and non- governmental organisations exacerbate the problem of low quality medicine if any?

In Sudan, the researchers did not identify any rigorous evaluations or quantitative studies about the impact of drug regulations on the quality of medicines and how to protect public health against counterfeit or low quality medicines, although it is practically possible. However, the regulations must be continually evaluated to ensure the public health is protected against fake medicines by ensuring the exclusive marketing of high quality medicines rather than commercial interests, and the drug companies are held accountable for their conducts [16].

\section{Medicines legislation framework in Sudan}

The availability of medicines in Sudan is controlled on the basis of safety, quality and efficacy. Thus, the government effects control in accordance with the Pharmacy, Poisons, Cosmetics and Medical Devices Act 2001 and its instruments. The Federal or State Departments of Pharmacy (DOP) and directives issued orders. The primary objective of both Federal and States' Departments of Pharmacy is to safeguard public health by ensuring all medicines and pharmaceuticals on the Sudan market meet appropriate standards of safety, quality and efficacy. The safeguarding of public health is achieved largely through the system of medicines' registration and licensing of pharmacy premises.

The first Pharmacy and Poisons Act was enacted in 1939. This Act had been amended three times since then. In 2001 amendments, cosmetics and medical devices were also brought under its purview. Thus, the name was changed to Pharmacy, Poisons, Cosmetics and Medical Devices Act (hereafter the Act). The Act regulates the compounding, sale, distribution, supply, dispensing of medicines and provides different levels of control for different categories e.g., medicines, poisons, cosmetics, chemicals for medical use and medical devices.

The Act makes provision for the publication of regulations and guidelines by the Federal Pharmacy and Poisons Board (FPPB), the pharmaceutical regulatory authority and its executive arm - the Federal General Directorate of Pharmacy (FGDOP). The FGDOP regulates mainly four aspects of medicines use: safety, quality, efficacy and price. Traditionally, governments in many countries, particularly developed nations have attempted to ensure the efficiency, safety, rational prescribing, and dispensing of drugs through premarketing registration, licensing and other regulatory requirements [17]. When applying to register the medicine manufacturers and importers are required to furnish the FGDOP with a dossier of information including among others, the indication of the medicine, its efficacy, side effects, contraindication, warnings on usage by high risk groups, price, storage and disposal [17].

The role of FGDOP includes among others:

1. Regulation and control of the importation, exportation, manufacture, advertisement, distribution, sale and the use of medicines, cosmetics, medical devices and chemicals;

2. Approval and registration of new medicines - the Act requires FGDOP should register every medicine before be sold or marketed. Companies are required to submit applications for the registration of medicines for the evaluation and approval;

3. Undertake appropriate investigations into the production premises and raw materials for drugs and establish relevant quality assurance systems including certification of the 
production sites and regulated products;

4. Undertake inspection of drugs' whole and retail sellers owned by both public or private sectors;

5. Compile standard specifications and regulations and guidelines for the production, importation, exportation, sale and distribution of drugs, cosmetics, etc.

6. Control of quality of medicines: This will be done by regular inspection and post-marketing surveillance;

7. Licensing of pharmacy premises (i.e., pharmaceutical plants, wholesalers and retail pharmacies);

8. Maintain national drug analysis laboratories for the pre- and post- marketing analysis of medicines;

9. Coordination with states departments of pharmacy to ensure the enforcement of the Act and its rules and directives.

Sudan medicines' quality measures

The following summarises the quality measures of all medicines.

\section{Registration of medicines}

The FGDOP is responsible for the appraisal, and registration of all medicines and other pharmaceuticals for both human and veterinary use on the Sudan market. It is also responsible for the verification of the competence of manufacturing companies, the manufacturing plants, the ability to produce substances or products of high quality before registering these companies and allowing them to apply for registration of their products in Sudan. When necessary, visits conducted to those companies and their manufacturing units, to verify their compliance with good manufacturing practice recommended by the WHO. The applicant for registration of pharmaceutical product must submit all prescribed data and the certificates required under the WHO certification scheme for a pharmaceutical product moving into international commerce, and any other information that is necessary for assuring the quality, efficiency and stability of the product through its shelf life [18].

\section{Licensing of pharmacy premises}

The licensing is a registration exercise to provide the DOP at state level (Federal level in case of local manufacturing plants) with the information necessary for the full implementation of the Act. Licenses are granted for a period of one year, and may be renewed at the end of December every year (applications to the relevant DOP before expiry of the current license). To improve the effectiveness of the public pharmacy, resources should be switched towards areas of need, reducing inequalities and promoting better health conditions. Medicines are financed either through cost sharing or full private. The role of the private services is significant. The present policy of the national health-care system in Sudan is based on ensuring the welfare of the Sudanese inhabitants through increasing national production and upgrading the productivity of individuals. The strategy of price liberalisation and privatisation had been implemented in Sudan over the last decade, and has had a positive result on government deficit.

There are three major licenses as follows:

\section{License a (Wholesaler License)}

The pharmaceutical importing companies have subjected to two broad categories of regulation. Those are the registration and administrative process, and the regulation of quality manufacturing standards, efficacy and information disclosure.
License A authorises the holder to sell a registered medicine to a person who buys the medicine for the purpose of sale or supply to someone else under the direct supervision of a registered pharmacist or licensed medical doctor. Licensing of the wholesalers involves identification of the wholesaler and suitability of the premise. There are 175 wholesalers in Sudan. The majority (162 wholesalers) are local agents for the goods manufactured from abroad. The rest are 13 "local manufacturer" wholesalers at Khartoum State (KS) and distribute the medicines to the whole country. Wholesalers are inspected by the state DOP before license is granted and thereafter at least once per year.

\section{License B (Retail Pharmacy License)}

Authorises the holder to sell a registered medicine to a patient on prescription or over-the counter basis under direct supervision of the registered pharmacist. The pharmacies are inspected before a license is issued and thereafter at least twice per year.

\section{License D (Manufacturer's License)}

Manufacturing includes many processes carried out in the course of making a medicinal product. A manufacturer's license covers all aspects- bulk drug, product manufacture, filling, labelling and packaging- under supervision of a registered pharmacist. There are 13 generic manufacturing sites at Khartoum State (KS). The Federal DOP inspects each one. Good manufacturing practice (GMP) is the basis of the inspection. Effective control of quality requires a manufacturer possess, and the appropriate facilities with respect to premises, equipment, staff, expertise and effective well-equipped quality control laboratory. Normally, before a license is granted, an inspection of premises is made and Federal DOP takes this into account. The local manufacturers produce 65 pharmaceutical dosage forms of essential drugs and cover $60 \%$ of the Central Medical Supplies Public Organisation (CMSPO) purchases. In Sudan there are two types of retail pharmacy:

\section{Commercial private pharmacies}

These are private establishments retailing registered drugs and medical supplies at a mark-up of $18 \%$. The source of the drugs and pharmaceuticals is private wholesalers. In 2002, though unlawful, the CMSPO started to sell its non-registered medicines to the private pharmacies. By the end of 2004, there were 779 private pharmacies in Sudan.

\section{People's pharmacies}

These are quasi-public establishments retailing drugs and medical supplies below the market prices to improve access and availability of pharmaceuticals. They were founded in the early 1980s as a pilot study for a drug cost recovery system. Those differ from the private commercial pharmacies. Firstly, in having access to the CMSPO drugs i.e., generic and large pack products, in addition the brand products from the private wholesalers. Secondly, the peoples' pharmacies are only owned by public organisations (e.g., hospitals, peoples' committees, trade unions and Non Governmental Organisations (NGOs)). Mark-up on cost for drugs from the CMSPO $(35 \%)$, and from private drug wholesalers (profit margin is $10 \%)$. However, they have become commercialised now and operate in a similar way to private pharmacies. The total number of such pharmacies was approximately 200 in Sudan. 
Rational for the research

The drug distribution network in Sudan during the past few years was in a state of confusion. It consists of open market, drug vendors (known as home drug store), community (private) pharmacies, peoples' pharmacies, private and public hospitals, doctors' private clinics, NGOs clinics, private medicines importers (wholesalers), public wholesalers (i.e., Central Medical Supplies and Khartoum State Revolving Drug Fund) and local pharmaceutical manufacturers. It is a common phenomenon in far states (e.g., Western and Southern states) to see street sellers or mobile sellers (hawkers) sell cigarettes, perfumes, orange and astonishingly medicines that range from Paracetamol and Aspirin tablets to antibiotics and anti-malarial drugs including injections. The medicines are usually left under the sun, and such conditions could facilitate the deterioration of the active ingredients.

The states' departments of pharmacy statutorily licensed community and Peoples' pharmacies. A superintending pharmacist, who is permanently registered with the Sudan Medical Council and licensed, oversees the pharmacy any time it is opened for business [19]. With such pharmacies there should not be any serious of the sale of fake drugs. Unfortunately, however there are many pharmacies working without qualified pharmacists.

This study is significant because the people right to health include the right access to a reliable standard of health care and assurance the medicines received are not only genuine but also safe, effective, of good quality and affordable [20]. The Sudan government has designed various ways to protect the public against low quality medicines. It is expected to equip the departments of pharmacy especially in remote areas, poor states with material and trained staff to effectively perform duties.

A recent unpublished post-marketing surveillance revealed that 35\% of the CMSPO samples and $16 \%$ of the private companies (registered products) samples obtained from different pharmacy shops failed to pass the quality test [20]. However, very few studies if any have been undertaken to evaluate the impact of the regulations put in place by the government long time ago.

This article should reveal strength and weaknesses of the legal pharmaceutical framework in Sudan from drug importers perspective. The findings of this investigation would be instructive to regulatory authorities in the developing countries. It also highlights how systematically the drug companies perceived the role of pharmacy regulations in assuring high quality of medicines and what suggestions (if any) they had to make in order to improve the regulatory framework.

\section{Methodology}

The article proposal was discussed to identify and improve the quality of medicines in Sudan. The survey was deliberately drug importers biased, as low quality medicines from informal sources will affect their business [21]. The authors then designed a selfadministered questionnaire of 14 close-ended questions and one open question. The questionnaire was designed to address main six issues:

- The quality of medicines.

- The consequences of splitting of the regulatory authority functions between the Federal Ministry of Health (FMOH) and the Ministry of Animal Resources (MOAR).
- Views on the role of the recently established Federal Pharmacy and Poisons Board, and Pre- and Post- Marketing Surveillance.

- Decentralisation, and

- Increased number of suppliers of non-registered medicines.

The final version of the questionnaire had been tested (three pharmacists working with drug companies in Sudan were asked to fill the questionnaire and feed the authors back whether there was unclear question or not). The questionnaire was tested to make sure all relevant issues were covered, pre-coded and adjusted before its distribution (Appendix 1).

\section{Appendix (1) Research Questionnaire}

Please mark the best answer with an $\mathrm{X}$

Example:

Strongly agree

Agree

Neither (agree or disagree)

Disagree

Strongly disagree

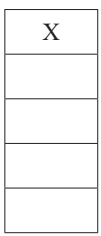

1. Thinking about pharmaceutical products available in Sudan today, would you consider medicines to be?

High quality

Generally of good quality

Low quality

Very low quality

I do not know

\begin{tabular}{|l|l|}
\hline & 1 \\
\hline & 2 \\
\hline & 3 \\
\hline & 4 \\
\hline & 5 \\
\hline
\end{tabular}

2. Do you agree or disagree the drug legislations prohibit marketing of low quality medicines in Sudan?

Strongly agree

Agree

Neither (agree or disagree)

Disagree

Strongly disagree

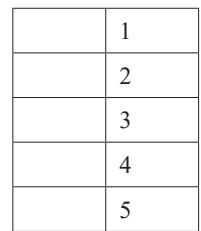

3. How much confidence do you have in the systems and safeguards currently in place to ensure the quality of drugs available in Sudan today?

Very confident

Somewhat confident

Not very confident

Not at all confident

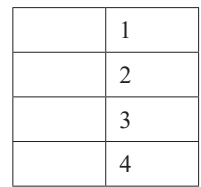

4. How much confidence do you have in the way the Federal government regulates and monitors quality of medicines?

Very confident

Somewhat confident

Not very confident

Not at all confident

\begin{tabular}{|l|l|}
\hline & 1 \\
\hline & 2 \\
\hline & 3 \\
\hline & 4 \\
\hline
\end{tabular}


5. After approval of the Pharmacy and Poisons Act 2001, the Ministry of Animal Resources took the responsibility of registration and control of veterinary medicines and the licensing of their premises. This action will: (Tick more than one)

Improve the quality control of medicines

Weaken the role of the Ministry of

Health in public health protection

Cause conflict between medicine control authorities

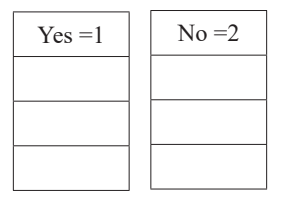

6. According to the Pharmacy and Poisons Act 2001, the authority of controlling quality of medicines and poisons was given to Federal Pharmacy and Poisons Board instead of the General Directorate of Pharmacy. This amendment:

Will improve the medicines quality assurance system

Will have no effect at all

Will to some extent, undermine the medicine quality control system

Will entirely undermine the medicine quality control system

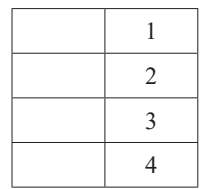

7. The provisions of the Pharmacy and Poisons Act 2001 gave the authority of licensing of pharmacies premises and their inspection to state health authorities. This action will enhance the medicines control:

\section{Strongly agree}

Agree

Neither (agree or disagree)

Disagree

Strongly disagree

\begin{tabular}{|l|l|}
\hline & 1 \\
\hline & 2 \\
\hline & 3 \\
\hline & 4 \\
\hline & 5 \\
\hline
\end{tabular}

8. Increased number of unregistered medicines importers will facilitate the marketing of low quality and counterfeit medicines:

Strongly agree

Agree

Neither (agree or disagree)

Disagree

Strongly disagree

\begin{tabular}{|l|l|}
\hline & 1 \\
\hline & 2 \\
\hline & 3 \\
\hline & 4 \\
\hline & 5 \\
\hline
\end{tabular}

9. Do you think that over the past four years, low quality (counterfeit) medicines in Sudan have?

Has not changed

Become less of a problem

Become more of a problem

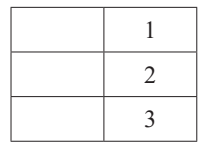

10. How serious a problem do you believe low quality medicines (counterfeit) are in Sudan today? Is this a problem that is?

Not at all serious

Not very serious

Somewhat serious

Very serious

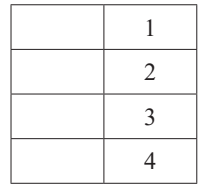

11. Are the recently updated medicines registration requirements sufficient to prohibit the marketing of low quality medicines?

Yes, sufficient

No, not sufficient

I do not know

\begin{tabular}{|l|l|}
\hline & 1 \\
\hline & 2 \\
\hline & 3 \\
\hline
\end{tabular}

12. Do you think the pre-marketing analysis of medicines is sufficient to assure their quality?

Yes, sufficient

No, not sufficient

I do not know

\begin{tabular}{|l|l|}
\hline & 1 \\
\hline & 2 \\
\hline & 3 \\
\hline
\end{tabular}

13. To ensure the overall quality of medicines used by consumers in Sudan today, do you believe that such pre-marketing analysis of medicines is?

Critically important

Important, but not critically

Not very important

\begin{tabular}{|l|l|}
\hline & 1 \\
\hline & 2 \\
\hline & 3 \\
\hline
\end{tabular}

14. Are you satisfied or dissatisfied with the current Sudan legal pharmaceutical framework in assuring medicines quality?

Very satisfied

Satisfied

Neither satisfied nor dissatisfied

Dissatisfied

Very dissatisfied

Not sure

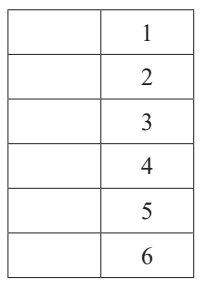

15. If you have any other comments about Sudan pharmaceutical legal framework, please do not hesitate to report them (Arabic comments are also be accepted)

The questionnaire was distributed to all forty participants at a seminar held in July 2004. Total numbers of drug importers companies were 175 in 2004. The seminar was organised by the FGDOP on the new proposal to limit (agree a ceiling for each item) the number of commercial brand product registered from each generic drug (the current situation is open). The owners and shareholders of drug companies were the participants. This was seen by the authors as a great opportunity to collect data of the drug importers' perspective on the quality of medicines. Hence, the study participants were so busy and it was very difficult to devote a time to be interviewed by the authors. In addition, the postal services in Sudan are poor (too slow and unreliable). 
Before the beginning of the seminar, the participants were requested by the secretariat to complete the questionnaire and hand it back to the secretariat before departure. The participants were informed it is anonymous questionnaire. The reasons given to the participants for filling out the questionnaire was to enable an academic research to assess the impact of the new Act on the quality of medicines. Finally, at the end of the seminar, the secretariat managed to get 30 questionnaires, representing $75 \%$ out of 40 distributed.

The information necessary to conduct this evaluation was collected from 30 pharmacists working with medicines' importing companies. Data gathered by the questionnaire were electronically analysed using Statistical Package for Social Sciences (SPSS) version 12.0 for windows.

\section{Result and Discussion}

The drug distribution network in Sudan consists of open market, drug vendors (known as home drug store), community (private) pharmacies, people's pharmacies, private and public hospitals, doctors' private clinics, NGOs clinics, private medicines importers (wholesalers), public wholesalers (i.e., Central Medical Supplies and Khartoum State Revolving Drug Fund) and local pharmaceutical manufacturers. The states' departments of pharmacy statutorily licensed community and Peoples' pharmacies. A superintending pharmacist, who is permanently registered with the Sudan Medical Council and licensed, oversees the pharmacy any time it is opened for business [22]. With such pharmacies there should not be any serious of the sale of fake drugs. Unfortunately however, there are many pharmacies working without qualified pharmacists [23].

During the last decade, the pharmacy workforces have witnessed a significant increase in the number of pharmacies, drug importing companies and pharmaceutical manufacturers as shown in Table 1. In the public sector, adoption of cost sharing policy as a mechanism of financing for essential medicines at full price cost requires far more expertise than simply distributing free medicines. This policy increases the demand for pharmacists in hospitals. The new concept of pharmaceutical care and recognition pharmacists as health care team members will boost the demand for the skilled PHRs. The Federal Ministry of Health $(\mathrm{MOH})$ faces two major issues with the PHRs: first, the current shortage of pharmacists in the public sector; secondly, the future role of pharmacists within the health cares system.

Table 1: Pharmacists labour market [23]

\begin{tabular}{|l|c|c|c|}
\hline Institutions & $\mathbf{1 9 8 9}$ & $\mathbf{2 0 1 5}$ & Increase in (\%) \\
\hline Faculties of Pharmacy & 1 & 7 & $600 \%$ \\
\hline Registered Pharmacists & 1505 & 2992 & $99 \%$ \\
\hline Public Sector Pharmacists & 162 & 300 & $85 \%$ \\
\hline Hospital Pharmacies & 205 & 304 & $48 \%$ \\
\hline Community Pharmacies & 551 & 779 & $41 \%$ \\
\hline Drug Importing Companies & 77 & 175 & $127 \%$ \\
\hline Drug Manufacturers & 5 & 14 & $180 \%$ \\
\hline
\end{tabular}

Table 2: Pharmacists distribution at state levels [24]

\begin{tabular}{|l|c|}
\hline State & Number of pharmacists \\
\hline $\begin{array}{l}\text { Department of Pharmacy (DOP) } \\
\text { Khartoum State* }\end{array}$ & 8 \\
\hline DOP-North Darfur & 7 \\
\hline DOP-Sennar & 2 \\
\hline DOP-North Kordofan & 5 \\
\hline DOP-South Kordofan & 7 \\
\hline DOP-White Nile & 2 \\
\hline DOP-Kassala & 7 \\
\hline DOP-River Nile & 3 \\
\hline DOP-Northern State & 3 \\
\hline DOP-Al Gezira* & 6 \\
\hline Total** & 50 \\
\hline
\end{tabular}

*The Pharmacists who work with Revolving Drug Funds are not included. **Information about other States is not available (10 Southern states, 2 Darfur states, 2 Eastern states, 1 Blue Nile state, and 1 West Kordofan state)

Around 3000 pharmacists are registered in Sudan. Only $300(10 \%)$ works with the public sector. 25, 25, 20 pharmacists were employed in Khartoum, Khartoum North and Omdurman hospitals respectively. Some states (e.g., Southern states has only 2 pharmacists) were not included in Table 2. This anomaly seems to imply the number of pharmacists in the public sector (has not only been insufficient in absolute terms, but also has been inefficient in its distribution). This number will be depleted and the situation may be getting worse. One reason is migration to the private sector. The results are described in (Figure 1).

In the absence of past baselines data, decisive conclusions should not be drawn from this article regarding the impact of the pharmaceutical regulations on ensuring good quality medicines. Nevertheless, the survey did serve to confirm the general impression about medicines of good quality on the Sudanese market.

$89 \%$ of respondents considered the medicines on the Sudanese market are generally of good quality. Although $55 \%$ of the study population either strongly agree $(21 \%)$ or agree $(34 \%)$ with the statement the drug legislations in Sudan prohibit marketing of low quality medicines. $35 \%$ believe the transfer of authority to recently established the Federal Pharmacy and Poisons Board (FPPB) will undermine on medicines quality assurance system. $38 \%$ of the participants thought the replacement of FGDOP by FPPB will improve the medicines quality control system.

Only one-fourth of respondents were not very confident in current systems and safeguard to ensure the quality of medicines. $69 \%$ of respondents were somewhat confident in FGDOP regulates and monitors quality of medicines. The majority $79 \%$ of respondents agree with the statement "decentralisation of licensing and inspection of pharmaceutical premises will improve the pharmaceutical control". After the approval of the Pharmacy and Poisons Act 2001, the Ministry of Animal Resources (dominated by veterinarians) took the responsibility of registration of veterinary medicines and the licensing of the whole and retail sellers of veterinary 
medicines. As expected, $91 \%$ of respondents thought, the splitting of drug registration between the $\mathrm{MOH}$ and the MOAR weakens the medicines control, compared with only $9 \%$ who thought the arrangement would improve the quality of medicines. One of the respondents added: "The splitting of the drug authority between $\mathrm{MOH}$, which according to the Sudan constitution is fully responsible for the public health and MOAR will create contradiction in lines of commands and public health would be compromised". $84 \%$ of respondents agreed with the statement "This new arrangement could cause conflict between two regulatory authorities"

$93 \%$ of participants either strongly agree $(73 \%)$ or agree $(20 \%)$ the increased number of non-registered medicines distributors will facilitate the marketing of low quality medicines (Figure 1). When asked about updated requirements of medicines registration, only $25 \%$ of respondents thought the updated requirements are not sufficient to prevent marketing of low quality medicines. Nearly three-quarters $(71 \%)$ agreed the pre-marketing surveillance is not enough to ensure the quality of medicines. The law regulating medicines was judged by the respondents as generally adequate $(68 \%)$.

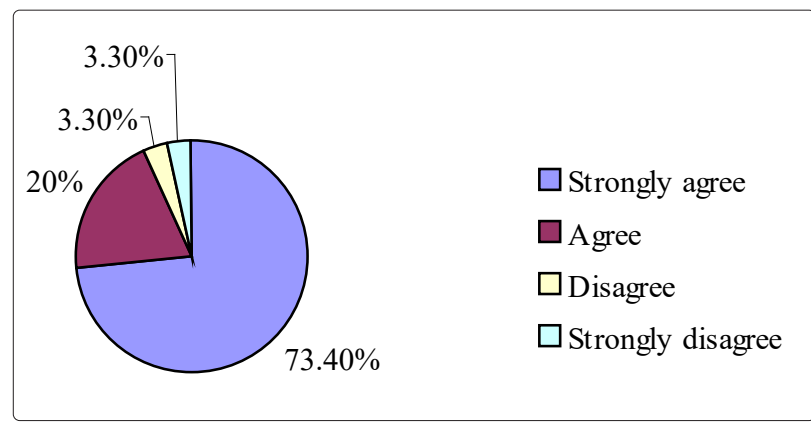

Figure 1: The increased numbers of non-registered medicines importers will facilitate the marketing of low quality medicines (30 pharmacists)

\section{Medicines supply system}

The Act, for the first time in Sudan has given the responsibility of veterinary medicines to separate committees. The Ministry of Animal Resources took the law "in hand", and started the registration of veterinary medicines and the licensing of the veterinary medicines premises. The conflict in the shared authorities between the Ministry of Health and the chairman of the FPPB lead to the freezing of the Board since October 2002. The FGDOP continues in the process of medicines registration, inspection of the pharmaceutical premises and the licensing as before establishment of FPPB.

The Act also obliges the states' governments to take all steps necessary to ensure compliance with marketing of registered medicines in licensed premises. But, the weaknesses of the regulatory infrastructure and lack of political commitment at state levels, the leakage of low quality, unregistered medicines to those states are highly suspected. This left the door widely opened for informal marketing of medicines particularly in far states. The states regulatory authorities should take the advantage of the legal authority granted by the Sudan constitution and the Pharmacy, Poisons, Cosmetics and the Medical Devices Act 2001 to enforce the regulations and increase the frequency of the inspection visits to drug companies and retail pharmacies.
Experience has shown the poor regulation of medicines can lead to the prevalence of substandard, counterfeit, harmful and ineffective medicines on the national markets and the international commerce. The Sudanese pharmaceutical legal framework was described as one of the strictest pharmaceutical system in the region. One of the great loopholes in this system was found to be the increased number of non-registered medicines-governmental sources such as the Central Medical Supplies Public Organisation (CMSPO) and notfor-profit non-governmental Organisations (NGOs). Respondents were hopeful the double standard of rules enforcement would be lifted after the new national unity government take over, arguing the current situation in which public organisations (such as the CMSPO) sell non-registered medicines to the private pharmacies could enhance trading of counterfeit medicines and create unfair competition environment.

One of the respondent reported, "It is disturbing, in spite of the existence of appropriate legislation, illegal distribution of medicines by the CMSPO. The CMSPO continues to flourish, giving the impression the government is insensitive to harmful effect on the people of medicines distribution unlawfully, and some are of doubtful quality". During the past three years the CMSPO started to sell unregistered medicines to the private pharmacies. The CMSPO practice (he added) will undermine the inspection and medicines control activities and ultimately jeopardise the health of the people taking medication.

Not surprisingly all respondents strongly agreed the increased number of sources of non-registered medicines will lead to entrance of low quality medicines. This result is inline with the WHO recommendation, which encourages the regulatory authorities and state members' government to register all medicines before the marketing. The medicines imported by public sector organisations are not excluded [25].

The FGDOP should define the norms, standards and specifications necessary for ensuring the safety, efficacy and quality of medicinal products. The availability, accuracy and clarity of drug information can affect the drug use decisions. The FGDOP does not have a welldeveloped system for pre-approval of medicines labels, promotional, and advertising materials. The terms and conditions under, which licenses to import, manufacture and distribute will be suspended, revoked or cancelled. This should be stringently applied to public, private and not-for-profit NGOs drug supplies organisations.

The predominant view, shared between the medicines' importers is the current pharmacy legislation to some extent satisfactory and managed to prohibit the marketing of low quality medicines. The recent post-marketing study carried by the National Drug Quality Control Laboratories, suggested the power of the current regulation is overestimated [26]. The finding of this article indicates the application procedures of the current measures to ensure the quality of medicines should be revisited. The technical complexity of regulations, political, commercial and social implications, makes necessary a degree of mutual trust between concerned stakeholders (i.e., suppliers, doctors, pharmacists, consumer representatives and government agencies).

\section{Conclusion and Recommendation}

The study reveals the need for further research to find out how efficient the regulatory authorities at both federal and state levels 
are. The research also needed to discover whether or not counterfeit medicines are sold on the Sudanese market.

From the data obtained in this article some general inferences could be made:

1. The brad outlines remain intact, but preventing drug smuggling across national boarders (Sudan shares frontiers with 9 countries) is hard to police.

2. The enforcement of the Act and its regulation governing the manufacture, importation, sale, distribution and exportation of medicines are not adequate enough to control the illegal importation and sale of medicines in Sudan.

3. The splitting of the drug regulatory authority between two ministries and the marketing of unregistered medicines by public drug suppliers (namely the CMSPO, and RDFs), and NGOs undermine the quality of medicines and ultimately jeopardise the health of the people taking medication.

4. In the light of the findings the following recommendations could be useful at various levels:

5. There is an urgent need for government to implement the provisions of existing Act.

6. The government should adequately equip and fund the National drug Analysis laboratories to start active post-marketing surveillance.

7. A more spirited effort need to be made by FGDOP and the States' Departments of Pharmacy to ensure all the medicines on the pharmacies' shelves are registered and come from legal sources.

8. The states' departments of pharmacies are not in existence should be re-established and invigorated. They should be adequately funded to be able to acquire the necessary facilities for their operations.

9. The CMSPO should stop importation, manufacture and distribution of unregistered medicines. It should also cease selling the tenders' product to the private pharmacies. The latter practice undermines the inspection outcomes, because it makes inspectors task too difficult (i.e., can not identify the source of medicine whether it is CMSPO or not).

\section{Ethical clearance and data protection consent}

Before starting the data collection, ethical clearance was obtained from the Federal Ministry of Health (MOH)-Research Ethics Committee. The first author signed the data protection consent and the respondents were informed it was an anonymous questionnaire and all the data collected are for the FGDOP assessment purpose. Nevertheless, the participants were also informed the data processing would not be used to support any decision-making and would not cause any damage, and distress them or to their business.

\section{Research limitations}

The selection of one group of stakeholders and ignorance of the rest (such as the CMSPO, retail pharmacies, drug manufacturers, NGOs, consumers organisations, policy-makers, regulators, police, customs, doctors, other health care professionals, and health professional unions, etc.) were not included. This means great caution must be exercised in any extrapolation to a country level statistical analysis, and percentage given must be regarded as rough estimates.

\section{Reliability and validity of the research instrument}

The sample chosen is indicative rather than fully representative and has been sized to be feasible in the time and resources available for the authors. However, the sample is thought to be sufficient to allow valid statistical analysis. Establishing the reliability and validity of measures are important for assessing their quality [7]. The mentioned time, and resources constraints did not allow the authors to test the reliability and validity of the research instrument.

\section{References}

1. Ministry of Health (MOH) (2001) Act 2001: Pharmacy, Poisons, Cosmetic and Medical Devices. Ministry of Health (MOH): Sudan.

2. Alubo SO (1994) Death for sale: A study of drug poisoning and deaths in Nigeria. Social Science \& Medicine 38: 97-103.

3. Andalo D (2004) Counterfeit drugs set alarm bells ringing. Pharmaceutical Journal 273- 341.

4. Bryman A (2004) Social Research Method. (2nd Edition). Oxford University Press.

5. Elfadil AA (2005). Quality assurance and quality control in the CMSPO.

6. Erhun WO, Babalola OO, Erhun MO (2001) Drug regulation and control in Nigeria: The counterfeit drugs. Journal of Health and Population in Developing Countries 4: 23-34.

7. Gamal K M, Omer A M (2006) A prescription for improvement: A short survey to identify reasons behind public sector pharmacists' migration. World Health and Population 2006: $1-24$

8. Helling-Borda M (1995) The role and experience of the World Health Organisation in assisting countries to develop and implement national drug policies. Australian Prescriber 20: 34-38.

9. Jallow M (1991) Evaluation of national drug policy in the Gambia, with special emphasis on the essential drug programme. University of Oslo: Norway.

10. Lexchin J (1990) Drug makers and drug regulators: Too close for comfort. A study of the Canadian situation. Social Science and Medicine 31: 1257-1263.

11. Lofgren H, Boer R (2004) Pharmaceuticals in Australia: developments in regulation and governance. Social Science and Medicine 58: 2397-2407.

12. Ministry of Health (MOH) (2003) 25 years Pharmacy Strategy (2002-2027). Khartoum: Sudan. Unpublished Report.

13. National Drug Policy (NDP) (1997) Ministry of Health (MOH): Sudan.

14. Osibo OO (1998) Faking and counterfeiting of drugs. West African Journal of Pharmacy 12: 53-57.

15. Ratanwijitrasin S, Soumerai SB, Weerasuriya K (2001) Do national medicinal drug policies and essential drug programmes improve drug use? A review of experiences in developing countries. Social Science \& Medicine 53: 831-844.

16. Rudolf PM, Bernstein IBG (2004) Counterfeit Drugs. New England Journal of Medicine 350: 1384-1386.

17. Shakoor O, Taylor RB, Behrens RH (1997) Assessment of the substandard drugs in developing countries. Tropical Medicines and International Health 2: 839-845.

18. Sibanda FK (2004) Regulatory excess: The role of regulatory impact assessment and the Competition Commission. In: Proceedings of the Pro-Poor Regulation and Competition Conference hosted by the Centre of Regulation and Competition (CRC), University of Manchester, UK, and the School of Public Management \& Planning, University of Stellenbosch, Cape Town, 7-9 September 2004.

19. WHO (1991) Counterfeit drugs: guidelines for the development 
of measures to combat counterfeit drug. Geneva: World Health Organisation. WHO/EDM/QSM/1990.1.

20. World Health Organisation / Drug Action Programme (WHO/ DAP). (1996). Comparative analysis of international drug policies. Report from the second workshop Geneva, June 1996.

21. WHO (2009) International drug policies. Geneva: Switzerland.

22. V. Velpandian, S. Elangovan, L. Naansi Agnes and M. Mohamed Musthafa (2014) Clinical Evaluation of Justicia tranquebariensis L. In the Management of Bronchial Asthma, American Journal of Phytomedicine and Clinical Therapeutics, AJPCT 9: 1103-1111.

23. K. Ravi Shankar N. Sita Ratna Kumari, GVN Kiranmayi (2014) In vitro Study of Antioxidant and Antimalarial Activities of New Chromeno-Pyrano-Chromene Derivative, American Journal of
Phytomedicine and Clinical Therapeutics, AJPCT 9: 1169-1176.

24. R Ramprabhu, Jairam A Karthik, K Ravikanth, Shivi Maini, Adarsh (2014). Evaluation of Regular Teat Sanitization Control Measures for Prevention of Sub Clinical Mastitis in Cattle, American Journal of Phytomedicine and Clinical Therapeutics, AJPCT 9: 1212-1216.

25. Abdeen M. Omer (2011) The impact of the pharmaceutical regulations on the quality of medicines on the Sudanese market: importers' perspective, Prime Journals of Business Administration and Management (BAM) 9: 295-302.

26. Abdeen M. Omer (2013) Chapter 5: Regulatory privatisation, social welfare services and its alternatives, In: Advances in Medicines and Biology 72: 69-86.

Citation: bdeen Mustafa Omer (2019) The Role and Experience of Sudan in Assisting To Develop and Implement National Drug Policies. Med Clin Res 4(11): 1-9.

Copyright: (C)2019 Abdeen Mustafa Omer. This is an open-access article distributed under the terms of the Creative Commons Attribution License, which permits unrestricted use, distribution, and reproduction in any medium, provided the original author and source are credited. 